\title{
Repensando o papel do professor como agente transformador: parresía, cuidado de si e ética na formação de professores ${ }^{1}$
}

\section{Rethinking the role of the teacher as transformation agent: parrhesia, care of the self and ethics in teacher education}

Alexandre Alves ${ }^{i}$

i Universidade do Vale do Rio dos Sinos, Educação, São Leopoldo, RS, Brasil. prof.alexandrealves@icloud.com

Resumo
O objetivo deste artigo é propor uma breve análise do conceito de parresía
nos últimos cursos de Michel Foucault no Collège de France para pensar o
papel do professor e sua formação na atualidade. Seguindo o argumento de
Foucault, analisa-se o conceito de parresía em contraste com o conceito de
confissão como operadores na constituição do sujeito ético em dois distintos
modos de subjetivação: nas escolas filosóficas da Antiguidade greco-romana
e no dispositivo pastoral cristão. Nas escolas filosóficas helenísticas, a figura
do mestre é central na formação do sujeito ético, como aquele que permite e
promove a autonomia do discípulo. Na prática cristã de condução, em
contrapartida, o objetivo é a mortificação da vontade e a subordinação
perpétua a um guia de conduta. Essa análise permite compreender como as
instituições e as práticas educacionais modernas e contemporâneas se
ancoram ainda na hermenêutica de si cristã, que é correlativa a formas
pastorais de condução e governo dos indivíduos. Para uma melhor
compreensão da questão, recorre-se à distinção, estabelecida por Jacques
Rancière, entre o professor como mestre emancipador e como cidadão.
Considera-se também o problema do "desaparecimento" do professor nos
discursos e nas práticas da “aprendizagem", seguindo a análise de Gert
Biesta. Por fim, são avaliadas algumas implicações da análise de Foucault
para repensar os dilemas da teorização educacional crítica hoje e o papel do
professor como intelectual específico na transformação das práticas
educativas.
Palavras-chave: Foucault, parresía, subjetividade, intelectual, formação de
professores

${ }^{1}$ Apoio: Coordenação de Aperfeiçoamento de Pessoal de Nível Superior 


\title{
pro.posições \\ e-ISSN 1980-6248
}

\begin{abstract}
The purpose of this paper is to propose a brief analysis of the parrhesia concept in the last courses of Michel Foucault at the Collège de France to rethink the importance of teachers and their education today. Following Foucault's argument, I analyze the concept of parrhesia in contrast to the concept of confession as operators in the constitution of the ethical subject in two distinct subjectivation modes: in the philosophical schools of GrecoRoman Antiquity and in the Christian pastoral dispositive. In the Hellenistic philosophical schools, the figure of the master is central in the formation of the ethical subject as that one who both allows and promotes the autonomy of the pupil. In the Christian practice of conducting, in contrast, the goal is the mortification of the will and the perpetual subordination to a conduct guide. This analysis allows us to understand how institutions and contemporary educational practices are still anchored in the Christian hermeneutics of the self, which is correlative to pastoral forms of conduct and government of individuals. In order to a better understanding of the issue, I turn to the distinction established by Jacques Rancière between the teacher as emancipatory master and the teacher as citizen. I also consider the "desapearance" of the teacher in the discourses and practices of "learning" following Gert Biesta's analysis. Finally, I evaluate some implications of Foucault's analysis for retbinking the dilemmas of critical educational theories today and the teacher's role as specific intelectual in the transformation of educational practices.
\end{abstract}

Keywords: Foucault, parrhesia, subjetivity, intelectual, teacher education

\section{Introdução}

A publicação dos cursos de Michel Foucault no Collège de France permitiu uma renovação da recepção de suas ideias na área educacional, tornando possível uma nova articulação entre ética, política e educação ${ }^{2}$. Como pontuou Alfredo Veiga-Neto (2009), é nos anos 2000 que "se entende melhor o recuo histórico e o correlativo deslocamento temático que Foucault efetuou ao entrar no terceiro domínio da sua obra - domínio do ser consigo" (p. 5). Conceitos dos últimos cursos de Foucault trazem elementos para superar os impasses da teorização educacional crítica na atualidade. Eles permitem questionar, de uma nova perspectiva, a fundamentação da ação docente e a racionalidade

${ }^{2}$ Um levantamento sistemático dessa recepção na área educacional no Brasil pode ser encontrado em Aquino, 2013. 


\section{pro.posıções}

pedagógica que lhe é correlativa. Neste artigo, minha intenção é analisar alguns dos usos e das relações possíveis da problematização da parresía nos cursos finais de Foucault no campo da formação de professores.

Entre as décadas de 1980 e 1990, o Foucault do Vigiar e punir foi muito utilizado na pesquisa em educação para repensar práticas de currículo e formas de poder nos dispositivos escolares. O recurso à "analítica do poder" permitia pôr em questão os discursos e as práticas que visam produzir um sujeito, ao mesmo tempo útil e dócil, por intermédio da maquinaria escolar. Faltou, porém, interrogar o próprio ato pedagógico, entendido como instância de subjetivação por meio de uma relação, mediada por um "mestre", entre o sujeito e a verdade. Os últimos cursos de Foucault e, em particular, a problematização das noções de cuidado de si e parresía como diálogo ou ética da palavra, constituem um poderoso instrumento para repensar essa dimensão da educação hoje ${ }^{3}$.

\section{A problematização da parresía no pensamento de Foucault}

Em seus últimos cursos e conferências, assim como no terceiro volume da História da sexualidade, nos quais a noção de "cuidado de si" exerce o papel central, Foucault tematizou as práticas de autoconstituição do sujeito ético na cultura antiga greco-romana. Considerando a dinâmica interna de seu pensamento, o foco se deslocava das técnicas de controle ou de governo dos homens, do ser-poder, para uma série de exercícios ou práticas que visavam transformar o próprio modo de ser do sujeito, o ser consigo. ${ }^{4}$ Nesse mergulho na cultura antiga, Foucault pretendia dar conta da proveniência do sujeito ético na cultura ocidental sem pressupor uma identidade ou uma essência autêntica a ser desocultada ou desalienada, ou seja, um sujeito substancial que

\footnotetext{
${ }^{3}$ Entre os estudos no campo educacional que se fundamentam em conceitos do Foucault tardio como "cuidado de si", "parresía", "psicagogia”, "regime de verdade", no Brasil e no exterior, destaco os seguintes: Besley, 2005, Freitas, 2013, Freitas, 2014, Huskaby, 2007, Marcello e Fischer, 2014 e Peters, 2007. Um levantamento e comentário do uso do conceito de "cuidado de si" nos estudos educacionais brasileiros recentes podem ser encontrados em Silva e Freitas, 2015.

${ }^{4}$ Utilizo a sistematização da obra de Foucault em três domínios, proposta por Veiga-Neto, 2014: o sersaber, que engloba o período da arqueologia do saber que se inicia com a História da Loucura; o ser-poder, que se refere aos estudos de Foucault sobre a analítica do poder, a partir de Vigiar e punir; e o ser-consigo, que inclui os últimos trabalhos de Foucault que enfocam a ética, a sexualidade e a subjetividade. Esses seriam os três eixos da ontologia histórica foucaultiana.
} 


\section{pro.posições}

serviria de fundamento para os discursos e as práticas. No lugar dessa antropologia universalista, que marca o pensamento filosófico moderno, Foucault propôs uma genealogia histórica que mapeia as diversas técnicas por meio das quais o indivíduo se constitui como sujeito de sua própria conduta.

Essas práticas de antoconstituição do sujeito são analisadas extensivamente no curso $A$ bermenêtica do sujeito (Foucault, 2001). Nesse curso, Foucault demonstrou como o princípio do "cuidado de si", entendido como incitação a ocupar-se consigo mesmo, como atenção diligente para com a própria conduta ética, tornou-se, no período helenístico, um verdadeiro fenômeno cultural que se refletia no ensinamento das diversas escolas filosóficas - estoica, epicurista, platônica, cínica, etc. Porém, é importante evitar a ideia difundida do Foucault final como um pensador "ético" que teria abandonado a preocupação com a política e com as relações de poder para refugiar-se no mundo dos ideais éticos criados pela Antiguidade clássica. Em seus últimos cursos, conferências e entrevistas, Foucault enfatiza constantemente que o cuidado de si deve ser visto como inseparável do cuidado do outro e que a dimensão política dessas práticas de autoconstituição jamais está ausente, pois "não há outro ponto, primeiro e último, de resistência ao poder político senão na relação de si para consigo" (Foucault, 2001, p. 241).

É em $A$ bermenêutica do sujeito que surge a primeira análise da parresía, entendida, ao mesmo tempo, como uma atitude e uma técnica que tornam possível o vínculo entre o cuidado de si (epimeleia heatou) e o conhecimento de si (gnothi seauton). A parresía aparece, nesse caso, como a abertura de mente, a palavra franca que deve intermediar a relação entre mestre e aluno, entre médico e paciente, entre o que guia e o que é guiado na prática helenística da direção de consciência. Entendida como "ética da palavra", a problematização da parresía, neste curso, tem uma dimensão pedagógica que permite repensar discursos e práticas no campo educacional.

No decorrer das aulas, Foucault analisa a parresía em relação ao imperativo ético do cuidado de si entre a época socrática e o período helenístico. Sua análise do diálogo Alcibiades de Platão evidencia que o cuidado de si não pode ser dissociado de sua função política. Nesse caso, o imperativo do cuidado de si aplica-se ao adolescente que deve aprender a ocupar-se de si mesmo para, mais tarde, poder ocupar-se dos outros, ou seja, 


\section{pro.posições}

exercer as magistraturas e garantir a glória da pólis. No período romano, entre os séculos I e II, em que as poleis já não eram o centro da vida política grega, tendo perdido em grande parte sua autonomia, o cuidado de si desvencilha-se do cuidado político da cidade e se autonomiza na forma de uma arte de viver (tekhnê tou biou) que pode ser praticada, em tese, por qualquer indivíduo durante toda a sua existência. Autonomizando-se em relação à sua função exclusivamente política e generalizando-se na sociedade, o cuidado de si passa a girar em torno da questão: que tipo de transformação o indivíduo deve praticar sobre si mesmo para aceder à verdade? A transformação de si passa a ser, assim, a condição de acesso à verdade. O critério de verdade torna-se o próprio modo de vida do sujeito.

Esse processo de transformação envolve, necessariamente, a relação entre um mestre, que enuncia a verdade, e um discípulo, que tem a obrigação de manter silêncio e deve lutar para apropriar-se da palavra verdadeira do mestre. O discípulo, então, colocase no dever de subjetivar o discurso do mestre para operar sua própria transformação.

A parresía é o que responde, do lado do mestre, à obrigação de silêncio do lado do discípulo. Assim como o discípulo deve se calar para operar a subjetivação de seu discurso, o mestre deve sustentar um discurso que obedece ao princípio da parresía se quiser que o que ele diz de verdadeiro torne-se enfim, ao termo de sua ação e de sua direção, o discurso verdadeiro subjetivado do discípulo. (Foucault, 2001, p. 348)

Nesse caso, a parresía é a "qualidade moral" exigida de todo sujeito que profere um discurso de verdade; é o que o torna apto a dizer a verdade. A análise de Foucault mostra como, no modo de subjetivação gestado nas escolas filosóficas da Antiguidade, a figura do mestre assume importância central na formação do sujeito ético, pois "torna-se um operador na reforma do indivíduo e na formação do indivíduo como sujeito. Ele é o mediador na relação do indivíduo com sua constituição de sujeito" (Foucault, 2001, p. 125). O mestre é um mediador necessário no processo de transformação da hexis, ou seja, o "modo de ser recebido", os "maus hábitos", o "comportamento vicioso" que precisam de correção. Das palavras do mestre, o discípulo deve fazer alguma coisa sua para, por seu turno, tornar-se um dia "sujeito de veredicção".

Nas escolas filosóficas pagãs, a direção é apenas provisória, pois o objetivo é conduzir o indivíduo a um estado em que não precise mais ser dirigido, em que atinja 


\section{pro.posıções}

pleno domínio de si, tornando-se soberano sobre sua vontade, seus atos e seus pensamentos. Portanto, nesse modo de direção de condutas, o mestre é aquele que promove a liberdade de ação do outro, é aquele, portanto, que conduz o outro, fazendo com que este se libere dos vícios, da intranquilidade, do mal, da infelicidade e assuma pleno controle sobre sua vida, sobre si mesmo. Ao atingir essa finalidade formadora, o mestre já não se faz mais necessário:

O objetivo da parresía é fazer com que, em um dado momento, aquele a quem se endereça a fala se encontre em uma situação tal que não necessite mais do discurso do outro. De que modo e por que não necessitará mais do discurso do outro? Precisamente, porque o discurso do outro foi verdadeiro. É na medida em que o outro confiou, transmitiu um discurso verdadeiro àquele a quem se endereçava que este então, interiorizando este discurso verdadeiro, subjetivando-o, pode se dispensar da relação com o outro. (Foucault, 2001, p. 458)

No curso O governo dos vivos, Foucault contrasta a parresía antiga com a confissão cristã. Ambas devem ser entendidas como práticas discursivas por meio das quais o indivíduo se constitui como sujeito de seus atos, desejos e pensamentos. Contudo, no dispositivo de subjetivação cristã, que é o correlativo de um poder pastoral $^{5}$, a verdade do sujeito emerge somente na medida em ele que renuncia a si mesmo, na medida em que abre mão da vontade própria e, voluntariamente, aceita obedecer perpetua e ininterruptamente a um outro. No cristianismo, o acesso à verdade só se dá na mortificação da vontade: para que o sujeito esteja apto à salvação, é preciso que ele se "converta", ou seja, rompa com seu modo de ser presente para "renascer" numa nova existência. A conversão não é um ato que se dá de uma vez por todas, mas implica uma luta sem trégua contra o "outro" dentro de si mesmo, uma penitência perpétua que

\footnotetext{
${ }^{5} \mathrm{O}$ poder pastoral havia sido analisado anteriormente por Foucault no curso Segurança, território, população (Foucault, 2004b) em termos de "governo dos indivíduos". Já no curso O governo dos vivos (Foucault, 2014), o filósofo analisa as práticas cristãs de direção, em contraste com a direção nas escolas filosóficas pagãs, a partir da relação entre subjetividade e verdade. Na aula de 19 de março de 1980, Foucault (2014) esclarece a distinção entre "poder pastoral" e "direção": "O próprio fato da direção, ou antes, a institucionalização da direção, o estabelecimento de uma técnica para dirigir aparece tardiamente no cristianismo. Claro, encontramos bem cedo, desde o início, o tema do poder pastoral, isto é, o fato de que deve haver à frente do rebanho um guia que o conduza para a salvação. ... Assim, esse tema pastoral é importante, é evidente, mas não coincide com a ideia ou com a técnica da direção. Não coincide com a ideia de uma intervenção permanente que seria a de um indivíduo sobre outro, tendo por fim observá-lo, conhecê-lo, guiá-lo, conduzi-lo ... ponto a ponto ao longo da sua existência numa relação de obediência ininterrupta" (p. 231).
} 


\section{pro.posições}

passa, necessariamente, pela confissão contínua das faltas a um guia que zela pela salvação de cada membro do rebanho.

A pastoral cristã, assim, criou um novo modo de subjetivação no qual o indivíduo é vinculado à sua própria identidade por meio da produção de uma verdade interior e a aceitação integral da submissão à vontade de um outro: "a pastoral preludia ... a governamentalidade pela constituição tão específica de um sujeito ... que é subjetivado pela extração da verdade que lhe é imposta" (Foucault, 2004 b, p. 188). No monarquismo cristão, em que foi gestado esse novo dispositivo de subjetivação, a obediência torna-se meio e fim de si mesma. Porque o mal está sempre à espreita, o monge cristão deve submeter-se exaustiva e indefinidamente à vontade de um outro, para o qual confessará, pondo em discurso, todos os cordis arcana (os "segredos do coração", na expressão de Cassiano), ou seja, todos os movimentos mais recônditos de sua alma.

Portanto, como podemos perceber pela comparação, parresía e confissão são práticas discursivas que induzem duas formas opostas de subjetivação. Na parresía, o discípulo deve absorver a palavra do mestre e fazer dela alguma coisa sua para poder tornar-se, por sua vez, algum dia "sujeito de veredicção". A obrigação de dizer a verdade, porém, reside toda do lado do mestre. Essa obrigação pode ser encarada tanto como a qualificação moral que se exige daquele que toma a palavra, quanto como uma técnica de transmissão da verdade própria ao discurso filosófico. Dessa forma, o mestre deve ter todo um cuidado, uma "prudência", para usar um termo-chave da ética aristotélica, no uso da palavra, avaliando com diligência as formas, o momento e a ocasião (o kairós) em que o indivíduo guiado está apto a receber a verdade. Já a confissão é um ato verbal por meio do qual o sujeito toma a si mesmo como objeto ou referente de seu discurso. $\mathrm{Na}$ confissão, o sujeito afirma tudo o que ele é, faz passar em discurso toda sua existência (suas faltas, seus defeitos, seus erros, suas falhas) e, dessa forma, se liga a essa verdade que ele próprio enunciou. Essa enunciação pressupõe dependência em relação a um outro, que recebe a confissão. Essa relação, por sua vez, é o que produz e modifica a relação que o sujeito tem consigo mesmo (Foucault, 2001, p. 353).

A parresía, em contrapartida, visa fazer com que aquele que a ela se submete constitua consigo mesmo uma relação autônoma, independente, plena e satisfatória, de tal forma que ele, em dado momento, não necessite mais da palavra do mestre. A parresía 


\section{pro.posições}

visa garantir, portanto, a autonomia do discípulo. Na confissão, ao contrário, institui-se uma dependência perpétua que se retroalimenta: quanto mais confesso, mais compreendo que sou culpado e mais preciso do discurso daquele (o pastor) que pode me transformar e me libertar. Diferente da parresía, na pastoral cristã a obrigação de dizer a verdade recai do lado do guiado e não daquele que guia. O próprio saber deste é desvalorizado na medida em que a verdade não vem do mestre, daquele que guia a alma, mas da revelação divina, do texto sagrado, cujos preceitos devem ser subjetivados. É a confissão, complementada pela penitência, que opera essa subjetivação, essa mutação interior.

Porém, essa transformação se dá ao preço da renúncia a toda vontade própria por parte do indivíduo que a ela se submete. É aí que reside a principal diferença com o cuidado de si antigo. Ao invés de instituir uma relação de autonomia e soberania consigo mesmo, na qual a parresía do mestre (o discurso franco de um guia que dirige e aconselha o guiado para que corrija seus erros e tenha consigo mesmo uma relação adequada) desempenha o papel central, o dispositivo pastoral vincula a subjetividade a um guia de conduta, com o qual se está em dívida perpétua. Foucault chama esse dispositivo pastoral de "hermenêutica de si" e afirma que dele provêm as instituições de controle e governo das condutas que garantem o funcionamento do poder no mundo moderno.

Origem da subjetividade moderna, a hermenêutica de si cristã estava ligada ao autossacrifício da individualidade, à renúncia e à mortificação da vontade em nome da salvação da alma. Nas conferências para o Dartmouth College, proferidas em 1980 (Foucault, 2013). Foucault mostra por que era necessário o retorno ao cristianismo para explicar a permanência da hermenêutica de si na modernidade. As mesmas técnicas - ou seja, a confissão contínua, o exame permanente, a subordinação perpétua à direção alheia - agora desvinculadas da obrigação da renúncia e do autossacrifício, portanto fora de um contexto especificamente religioso, foram utilizadas pela cultura ocidental como apoio necessário e indispensável para suas instituições de governo dos indivíduos. As tecnologias do eu herdadas do monasticismo cristão são, portanto, a condição da governamentalização generalizada da sociedade que se observa no Ocidente moderno.

É importante reconhecer a permanência dessa forma de subjetivação pastoral na atualidade, mesmo e principalmente quando surge disfarçada por trás de práticas que se 


\section{pro.posições}

pretendem libertadoras. Para dar um exemplo, na escola contemporânea, o estímulo a "extravasar", "botar para fora", "dizer o que se pensa" tem clara função confessional e, portanto, apenas reconduz uma perpétua heteronomia (Larrosa, 1994, p. 44). Dizer tudo o que se pensa não se confunde com a parresía, que pressupõe um "contrato parresiástico" por meio do qual o discípulo aceita a direção de um mestre que se empenha para que aquele tenha consigo próprio uma relação autônoma e, portanto, de soberania e autocontrole (Foucault, 2004a, p. 99). Deste ponto de vista, um ensino permissivo que aceita, e mesmo estimula, o descontrole emocional não contribui de nenhuma maneira para a autonomia dos educandos.

Diferente do mero extravasamento emocional, a "franqueza" da parresía pressupõe toda uma técnica e uma ética do silêncio e da escuta, que permitem a subjetivação do discurso verdadeiro veiculado pelo mestre. A parresía implica uma forma de ser em que se é aquilo que se diz e se faz e se diz aquilo que se é: dizer, ser e fazer convergem numa ética da palavra que vincula educador e educando. Enquanto a confissão nos prende cada vez mais a nós próprios, a parresía nos encoraja a nos desprender daquilo que somos e a sermos outros, de certa forma estrangeiros a nós mesmos. Foucault (2011, pp. 43-44) nos lembra de que a relação com o outro é condição necessária e indispensável para o cuidado de si. Para o estabelecimento de uma relação adequada, soberana, autônoma comigo mesmo, necessito da condução e da palavra franca de um outro.

\section{O intelectual e as políticas da verdade}

A pesquisa de Foucault sobre a parresía responde à necessidade de encontrar um ponto em comum entre a ética e a política, entre o cuidado de si e o cuidado dos outros, entre as práticas do autogoverno e o governo da cidade. Sem a parresía, o princípio do cuidado de si seria apenas uma espécie de dandismo moral, um modo de relação consigo de natureza narcísica e individualista. A "dobra" entre o cuidado de si e o cuidado do outro é operada justamente pela parresía como ética da palavra, que implica a coincidência entre o sujeito da enunciação e o sujeito da conduta. Nesse sentido, a parresía se apresenta 


\section{pro.posições}

como um modelo de conduta que permite ao indivíduo dobrar as relações de poder estabelecidas e criar novos espaços de diálogo e de interação.

O modelo da parresía permite pensar a estilização da vida e a produção da subjetividade como formas de resistência ao avanço e ao enrijecimento das relações de poder. Na visão de Foucault, a palavra de verdade, o logos, tem poder transformador, mais que isso, transfigurador da vida, do bios, na medida em que se estabelece uma relação direta e pessoal com a verdade:

A parresía é uma atividade verbal na qual um falante expressa sua relação pessoal com a verdade e arrisca sua própria vida porque reconhece o dizer a verdade como um dever para melhorar ou ajudar outras pessoas (e também a lugar da persuasão, a verdade em lugar da falsidade ou do silêncio, o risco de morte em lugar da vida e a segurança, a crítica em lugar da adulação e o dever moral em lugar do interesse próprio e da apatia moral. (Foucault, 2004a, p. 46)

Insistindo sobre a necessidade de uma relação pessoal com a verdade como critério do discurso parresiástico, Foucault (2004a) pretende igualmente "construir uma genealogia da atividade crítica na filosofia ocidental” (p. 213). Nessa genealogia, há duas vertentes do discurso verdadeiro que remontam a Platão. De um lado, a "analítica da verdade", que busca os critérios que permitem reconhecer se uma proposição é verdadeira ou falsa. De outro lado, a tradição "crítica", que interroga quem é capaz de dizer a verdade (quem é o parresiastés), como é possível reconhecê-lo e qual a importância de dizer a verdade. Da analítica da verdade provêm os procedimentos lógicos e dialéticos que determinam como estabelecer a verdade ou a falsidade dos juízos. Da tradição crítica, deriva a figura do intelectual como aquele que faz uso da liberdade de palavra para opor o poder da verdade à verdade do poder.

É essa problematização ético-política do discurso verdadeiro que interessa a Foucault. Ele não pretende tematizar os critérios internos ou externos para a obtenção da verdade, mas a própria atividade de dizer a verdade, a veredicção como atividade. Foucault questiona, numa perspectiva genealógica, não o problema metafísico clássico: “o que é a verdade?", mas questões de outra natureza: “quem está apto a dizer a verdade?”, “sobre o que se pode dizer a verdade?”, “quais as consequências de dizer a verdade?”, “qual a relação entre o dizer a verdade e o exercício do poder?” 


\section{pro.posições}

A problematização da parresía, nos últimos cursos e conferências de Foucault, conecta-se, assim, com sua preocupação com o papel do intelectual na contemporaneidade e com o que ele chama de "políticas da verdade" ${ }^{6}$. Numa entrevista da década de 1970, Foucault (1994) já problematizava essas questões:

Considero que o papel do intelectual hoje não é o de dar a lei, propor soluções, profetizar, pois, nessa função, ele só pode contribuir para o funcionamento de uma situação de poder determinada que deve, na minha opinião, ser criticada. (p. 905)

Foucault contrapõe dois modelos da atividade crítica exercida pelo intelectual na Europa moderna: o intelectual universal e o intelectual específico. $O$ modelo por excelência do "intelectual universal" pode ser encontrado na obra e na figura de JeanPaul Sartre. Para Sartre, o intelectual é uma consciência dilacerada entre o universal e o particular e a ele cabe a "decisão" existencial de engajar-se ao lado da massa oprimida ou renunciar à própria consciência, acomodando-se ao existente. Ele seria, assim, o representante e portador da universalidade que, por intermédio de sua escolha existencial, fala em nome de todos os que não têm voz. Foucault, em contrapartida, faz a defesa do “intelectual específico", aquele que politiza sua conduta a partir da atividade específica que exerce no interior de um domínio determinado e a partir do lugar concreto que ocupa. São as relações estabelecidas entre teoria e prática no Ocidente moderno que Foucault põe em questão.

$\mathrm{Na}$ tradição francesa, o intelectual "universal" era, por excelência, o écrivain que punha seu verbo e sua verve a serviço da causa dos dominados, baseado em valores universais. Assumindo o papel de "funcionário do universal", o écrivain (pensemos num Voltaire ou num Zola) opõe ao despotismo e à arrogância dos ricos, aos abusos dos poderosos a universalidade da lei e da justiça. Foucault, no entanto, detecta a partir do fim da Segunda Guerra o ocaso dessa figura sacralizada do intelectual universal, com a crescente divisão do trabalho e a extensão do aparato técnico-científico na sociedade e na economia. Em seu lugar, surge o intelectual específico, portador de certo saber, de certo know-how, de certa competência profissional que lhe determinam uma relação com a

${ }^{6}$ Para uma análise da reflexão sobre o papel do intelectual em Foucault, dos debates da década de 1970 ao Foucault tardio, ver Yazbec, 2012. 


\section{pro.posições}

verdade que pode ser ou não politizada. É nesse sentido que Foucault (1996) fala de uma "política da verdade" para problematizar o papel do intelectual na atualidade:

O problema político essencial para o intelectual não é criticar os conteúdos ideológicos que estariam ligados à ciência ou fazer com que sua prática científica seja acompanhada por uma ideologia justa; mas saber se é possível constituir uma nova política da verdade. O problema não é mudar a "consciência" das pessoas, ou o que elas têm na cabeça, mas o regime político, econômico, institucional de produção da verdade. (p. 14)

\section{O professor como intelectual específico}

Mas, como podemos utilizar a problematização foucaultiana da parresía para pensar as práticas de liberdade no campo educacional e, em especial, para repensar a formação do professor? Será que a ética da palavra que intermediava a relação entre mestre e discípulo nas escolas filosóficas da Antiguidade poderia ser reatualizada e servir como modelo de novas práticas pedagógicas? Há alguns problemas em pensar essa transposição sem as mediações necessárias. Em primeiro lugar, o que Foucault se propõe é fazer uma análise genealógica ou histórica. Seu texto, assim, não tem nenhum caráter prescritivo. Foucault não está dizendo que devíamos substituir nossas práticas pedagógicas atuais por outras melhores, inspiradas na Antiguidade greco-romana. Em segundo lugar, embora em $A$ hermenêtica do sujeito a relação entre práticas de si e pedagogia seja constante durante todo o curso, temos que reconhecer que essas práticas se referem essencialmente aos adultos, o que torna sua extrapolação para o contexto escolar problemática. $\mathrm{Na}$ análise foucaultiana do Alcibíades, o cuidado de si é apresentado como complemento a uma paideia insuficiente do futuro governante da pólis, mas será que a "erótica da verdade" socrática, que vinculava mestre e discípulo, serviria hoje de referência pedagógica? No período helenístico, por sua vez, a prática do cuidado de si exigia que à palavra verdadeira e franca do mestre (a parresía) correspondesse o silêncio reverente do discípulo. Mas isso não nos remeteria a uma pedagogia conservadora, que não deixa voz ao aluno?

Mas, justamente, o contrassenso só ocorre quando tentamos derivar dessas análises modelos pedagógicos concretos ou receitas práticas. Como adverte Jean-Pierre 


\section{pro.posıções}

Audureau (2003, p. 26), num artigo sobre o uso de Foucault nos estudos em educação, somos obrigados a reconhecer que não é possível fazer um "uso forte" da analogia entre nosso presente e o mundo antigo greco-romano a ponto de derivar dele um modelo alternativo à pedagogia disciplinar e às formas de condução biopolíticas. O próprio Foucault (2004a) adverte que "a parresía não pode, em seu sentido grego, dar-se mais em nosso moderno marco epistemológico" (p. 40). A arqueologia do discurso parresiástico, porém, pode ter um papel crítico na problematização das práticas pedagógicas e na busca por caminhos alternativos. Um desses caminhos é repensar a figura do professor como intelectual específico.

De acordo com Foucault (1994), é tarefa do intelectual identificar, a partir do ponto no qual nos encontramos, onde a ruptura é possível. Contudo, para isso, ele tem que renunciar à função profética para "indicar nas inércias e coações do presente os pontos fracos, as aberturas, as linhas de força” (p. 268). A prática historiográfica arqueogenealógica, proposta por Foucault, assume o papel de força crítica quando busca mostrar a contingência radical de toda forma de poder e a possibilidade sempre presente da transformação. Nesse sentido, ela permite sair dos impasses da teorização educacional crítica, para "pensar diferentemente" a educação e poder gestar novas práticas de liberdade no contexto escolar. Entendo por "teorização educacional crítica" as teorias da educação que não visam à adaptação ou ao ajustamento ao existente, mas à transformação da ação educativa e ao aumento do grau de autonomia dos sujeitos envolvidos no processo educativo.

Seria interessante recorrer aqui à diferenciação, feita por Jacques Rancière, entre o "professor", o "cidadão" e o que ele chama de "mestre emancipador", para entender alguns dos impasses das teorias críticas da educação. Segundo Rancière (2005), o "professor" é o profissional que exerce um certo papel social e institucional no contexto escolar ou universitário; o "cidadão" é aquele que deseja o bem da humanidade ou da comunidade, militando para sua realização; o "mestre emancipador", por sua vez, é aquele que trabalha ativamente pela autonomia intelectual do educando, torna possível sua emancipação mental e promove sua liberdade de ação. $O$ ponto a ressaltar é que essas três figuras - o "professor", o "cidadão" e o "mestre emancipador" - jamais convergem para uma mesma identidade. 


\section{pro.posições}

Daí as inevitáveis tensões que surgem quando pensamos a atuação dos professores como intelectuais específicos. Como "professor", tenho certas obrigações institucionais, tais como: administrar conteúdos e currículos, controlar frequência e participação em sala, ministrar avaliações, prestar contas à instituição que me emprega. Como "cidadão", tenho uma certa concepção da boa vida, do bem comum, pelos quais luto e me empenho, seja por meio da expressão de minhas ideias e opiniões, seja por meio do ativismo e da militância política. Essas duas posições podem convergir ou divergir mais ou menos, criando inevitáveis dilemas e tensões no cotidiano dos professores. Para Paulo Freire, por exemplo, o primado deve sempre caber ao "cidadão", que se entende como "intelectual orgânico", necessariamente ao lado dos oprimidos e, portanto, contra as práticas que reproduzem a opressão e as hierarquias sociais. Para Freire, portanto, não há distinção ou lacuna entre emancipação individual e práxis política. De acordo com Rancière, entretanto, o "mestre emancipador" não se confunde nem com o "professor", como profissional num contexto institucional, nem com o "cidadão", como militante e ativista. O "mestre emancipador", sendo aquele que trabalha pela autonomia intelectual do educando, jamais se coloca na posição de "instrutor de coletividades", jamais assume o papel do pastor que conduz um rebanho:

Ele jamais se dirige senão àquele que se dirige a ele. Ele está diante de alguém que quer entrar no país do saber e lhe pergunta: ... O que você procura no país do saber é a confirmação de sua ignorância ou da incapacidade comum ou é o crescimento de sua própria capacidade? (Rancière, 2005, p. 29)

O mestre emancipador deve saber pôr em questão seu próprio saber, renunciando a colocar-se na posição de "guia de conduta" ou pastor que levará o rebanho ao bom caminho, ao "país do saber". Recusando o papel de "libertador" ou "salvador" do educando, o mestre emancipador não corre o risco de substituir a formação pela doutrinação político-ideológica. Se o fizesse, estaria reafirmando o governo de condutas próprio do poder pastoral e, portanto, deixando de contribuir para a autonomia do educando. Ele deve admitir que a emancipação intelectual é uma tarefa individual, compete àquele que aprende e não àquele que ensina, que pode apenas criar as condições para que ela ocorra. A teorização educacional crítica tem que saber reconhecer 


\section{pro.posições}

o caráter necessariamente individual da emancipação, para ser capaz de pôr em questão o ato pedagógico e os processos de subjetivação por ele pressupostos.

Voltando a Foucault, agora podemos entender melhor a insistência em sua obra tardia, nos modos e nas técnicas de subjetivação. Foucault nunca deixou de ser um pensador da emancipação, das práticas de liberdade. Porém, em diversas ocasiões reconheceu que a mera desrepressão não é condição suficiente (embora não deixe de ser condição necessária) para a emancipação. Foucault enfatizou a ideia de que as práticas de liberdade não podem ser reduzidas a práticas de "liberação", que pressupõem o retorno ou a reapropriação de uma essência humana que teria sido alienada. No mundo escolar, o que Foucault chama de "liberação" pode ser entendido como o relaxamento das coações disciplinares mais brutais do passado, processo histórico que ocorreu no mundo ocidental no período do segundo pós-guerra no contexto das mobilizações estudantis que têm, no maio de 1968, seu ícone máximo. Porém, o questionamento do ensino centrado no poder e na autoridade magistral contribuiu para o surgimento de uma concepção da educação em que há o apagamento da figura do mestre e a denegação do próprio processo educativo como uma forma de condução.

A partir dos anos 1990, dá-se a ascensão dos discursos e das práticas centrados nos conceitos de "aprendizagem" (learning), em que os educandos são redefinidos como "aprendizes", as escolas como "ambientes de aprendizagem" e os professores como "facilitadores da aprendizagem". Esse processo é tematizado nos estudos de Gert Biesta, que abordam a formação de professores a partir de uma perspectiva pós-estruturalista na Filosofia da Educação (Biesta, 2012, 2013a, 2013b).

Como argumenta Biesta (2013b, p. 451), ao criticar a pedagogia tradicional, o pensamento construtivista acabou por desacreditar o chamado "modelo de transmissão do ensino", segundo o qual o professor é aquele que conduz o aluno da ignorância ao conhecimento ou à verdade. Com a voga do construtivismo, surgiram as pedagogias centradas no aluno e as pedagogias do interesse, que marginalizam a figura do professor no processo educativo, atribuindo-lhe um papel de mero coadjuvante ou intermediário na aprendizagem do aluno. De acordo com essa concepção, os estudantes "usam" o professor como usariam qualquer outra fonte de informação, como um livro ou a internet, para aprender conteúdos considerados interessantes ou motivadores. 


\section{pro.posições}

O problema com essa concepção de educação é que ela parte do pressuposto de que o aprendizado deve estar sob o controle constante do aluno. Portanto, é uma educação em que não há lugar para "verdades inconvenientes", temáticas polêmicas ou conceitos difíceis. É uma educação que apenas reforça e corrobora aquilo que o aluno já traz, ao invés de dar-lhe a oportunidade de vivenciar a educação como uma experiência transformadora. Biesta (2013b) defende a irredutibilidade do ensinar ao aprender como processos: "aprender com alguém é uma experiência radicalmente diferente da experiência de ser ensinado por alguém" (p. 457).

A valorização das teorias construtivistas da aprendizagem associa-se à imposição da lógica de mercado às escolas, com o consequente processo de "managerialização" das escolas e universidades. A produção de amontoados de dados por sistemas de avaliação e testes padronizados permite o controle gerencial do processo educativo, estimulando a comparação e a concorrência entre instituições de ensino, como se fossem empresas competindo num mercado. A redefinição das escolas e das universidades como provedoras de "serviços de ensino" e dos alunos e pais como "clientes" retira do professor o seu papel tradicional e lhe atribui um papel apenas burocrático como facilitador de fluxo ou controlador dos processos que gerencializam o ensino. Sujeitando educadores e educandos aos imperativos do mercado, os discursos e as práticas da “aprendizagem", portanto, contribuem para uma crise de meios e fins na educação e para uma crise da própria figura do educador.

Assim, a reflexão de Foucault sobre o papel pedagógico da parresía e a centralidade da figura do mestre nas práticas de si antigas assumem uma enorme importância para repensar o papel do docente e sua formação na atualidade. A figura do docente como "mestre emancipador", para retomar a expressão de Rancière, é essencial, se queremos que o ensino tenha caráter transformador. O próprio ato de ensinar só adquire significado se torna possível trazer ao mundo algo radicalmente novo e singular, algo não previsto, não antecipado, algo que até mesmo transcenda o horizonte de possibilidade dado. São justamente a incerteza e o risco, associados ao ato de ensinar, que o tornam uma experiência transformadora, a qual não apenas confirma o que existe, mas abre novas possibilidades de ser e existir no mundo. 


\section{pro.posições}

Ao ser transformado numa questão meramente técnica, o ato pedagógico perde qualquer dimensão ética ou política. Repensar a educação como uma prática de liberdade, que promove a independência e o diálogo dos sujeitos envolvidos no processo educativo, exige que se ponham novamente em questão a dimensão ética e as implicações políticas do ato pedagógico. Para isso, os últimos cursos de Foucault no Collège de France fornecem um farto material para reflexão e debate.

\section{Conclusão}

Foi minha intenção neste artigo apresentar uma das formas de nos apropriar do pensamento do Foucault tardio para pensar a produção da subjetividade na educação e a formação de professores. Essa é apenas uma maneira possível de nos apropriar do rico ferramental do filósofo e historiador francês para repensar nossa relação com o conhecimento, com o ensino e com nós mesmos, como sujeitos da educação. A análise genealógica da noção de parresía permite abrir novas veredas para a teorização educacional crítica, que, muitas vezes, se rende a um populismo fácil, dogmático e desprovido de risco. Ela permite pensar a crítica de outra maneira, como um processo duplo: de um lado, como resistência e engajamento arriscado na transformação das instituições e, de outro, como autoquestionamento permanente.

Como atitude, a parresía implica o face a face com as instâncias dominantes e não apenas a negação abstrata (e retórica) do existente. Como mostra a análise de Foucault, parresía não é a demonstração da verdade por oposição à inverdade ou à falsidade; é a crítica direta, franca e corajosa do interlocutor tanto quanto a autocrítica do próprio locutor. Há parresía, por exemplo, quando o filósofo critica o tirano (como Platão diante do tirano de Siracusa) ou quando o cidadão critica a opinião da maioria numa assembleia pública. A parresía só existe quando o locutor se encontra em situação de inferioridade e, portanto, de risco, em relação ao interlocutor, seja ele um tirano, uma autoridade, um professor ou uma assembleia. Podemos falar em parresía quando um estudante questiona um professor ou gestor autoritário, ou quando estudantes e professores juntos se manifestam para questionar burocratas e autoridades sobre políticas educacionais autoritárias e equívocas. 


\section{pro.posıções}

Resulta dessa reflexão sobre o conceito de parresía que uma nova ética da palavra, que contribua para estabelecer um vínculo autônomo entre os sujeitos da educação, e uma nova política da verdade, que permita o diálogo e a mobilização por uma educação mais democrática, são essenciais na transformação da realidade atual. Porém, não poderíamos derivar da tradição, tomada como matriz, um modelo já pronto. Não há receita. Se é verdade que nos faz falta uma ética da palavra e uma política da verdade, é também forçoso admitir que esta tem que primeiro ser inventada, do mesmo modo que precisamos nos reinventar diariamente como sujeitos da educação.

\section{Referências Bibliográficas}

Aquino, J. G. (2013). A difusão do pensamento de Michel Foucault na educação brasileira: um itinerário bibliográfico. Revista Brasileira de Educação, 18(53), 301-324.

Audureau, J.-P. (2003). Assujettissement et subjectivation: réflexions sur l'usage de Foucault en éducation. Revue française de pédagogie, 143(1), 17-29.

Besley, T. (2005) Foucault, truth telling and technologies of the self in schools. Journal of Educational Enquiry, (6), 76-89.

Biesta, G. J. J. (2012) Giving teaching back to education: responding to the disappearance of the teacher. Phenomenology and Practice, 6(2), 35-49.

Biesta, G. J. J. (2013a). Para além da aprendizagem. Educação democrática para um futuro bumano. Belo Horizonte: Autêntica. 
Biesta, G. J. J. (2013b). Receiving the gift of teaching: from 'learning from' to 'being taught by'. Studies in Philosophy and Education, 32(5), 449-461.

Foucault, M. (1994). Dits et écrits (vol. II). Paris: Gallimard.

Foucault, M. (1996). Microfísica do poder (12a ed.). Rio de Janeiro: Graal.

Foucault, M. (2001). L’herméneutique du sujet (Cours au Collège de France [1981-1982]). Paris: Gallimard/Seuil, 2001.

Foucault, M. (2004a). Discurso y verdad en la antigua Grecia. Barcelona/Buenos Aires/México: Ediciones Paidós.

Foucault, M. (2004b). Securité, territoire, population (Cours au Collège de France [19771978]). Paris: Gallimard/Seuil.

Foucault, M. (2011). A coragem da verdade (Curso no Collège de France [1983-1984]). São Paulo: Martins Fontes.

Foucault, M. (2013). L'origine de l'herméneutique de soi (Conférences prononcées à Dartmouth College, 1980). Paris: Vrin.

Foucault, M.(2014). O governo dos vivos (Curso no Collège de France [1979-1980]). São Paulo: Martins Fontes.

Freitas, A. S. de. (2013). A parresía pedagógica de Foucault e o êthos da educação como psicagogia. Revista Brasileira de Educação, 18(53), 325-338.

Freitas, A. S. de. (2014). O cuidado de si e os perigos de uma ontologia ainda sem cabimento: o legado ético-espiritual de Foucault. Pro-Posições, 25(2), 121-138.

Huskaby, M. F. (2007). Conversation on practices of the self within relations of power: for scholars who speak dangerous truths. International Journal of Qualitative Studies in Education, 20, 513-529.

Larrosa, J. (1994). Tecnologias do eu e educação. In T. T. da Silva (Org.), O sujeito da educação - estudos foucaultianos (pp. 35-86). Petrópolis: Vozes. 


\section{pro.posições}

Marcello, F. de A., \& Fischer, R. M. B. (2014). Cuidar de si, dizer a verdade: arte, pensamento e ética do sujeito. Pro-Posições, 25(2), 157-175.

Peters, M. A. (2007). Truth-telling as an educational practice of the self: Foucault, 'Parrhesia' and the Ethics of Subjectivity. Oxford Review of Education, 29, 207-224.

Rancière, J. (2005). L'actualité du 'Maitre ignorant'. Le Télémaque, 1(27), 21-36.

Silva, N. M. A. da, \& Freitas, A. S de.(2015). A ética do cuidado de si no campo pedagógico brasileiro: modos de uso, ressonâncias e desafios. Pro-Posições, 26(1), 217-233.

Veiga-Neto, A.(2009). Editorial. Revista Educação \& Realidade, 34(2), 5-9.

Veiga-Neto, A. (2014). Foucault \& a Educação. Belo Horizonte: Autêntica.

Yazbec, A. C. (2012). A “transgressão do universal”: o intelectual e o poder em Michel Foucault. Kriterion, 125, 251-262.

Submetido à avaliação em 31 de março de 2016; aprovado para publicação em 26 de agosto de 2016. 